\title{
Chapter 6 \\ Workforce Skills Curriculum Development in Context: Case Studies in Rwanda, Algeria, and the Philippines
}

\author{
Catherine Honeyman, Laura Cordisco Tsai, Nancy Chervin, Melanie Sany, \\ and Janice Ubaldo
}

\begin{abstract}
Life skills programming in the field of international workforce development operates within a professional community of practice that is shaped by dynamics of power, influence, and resources, as well as by specific local contexts and actors. This chapter gives detailed insight into three case studies of youth workforce life skills programming developed by the organizations World Learning, Education Development Center, and 10ThousandWindows in different national settings and with distinct youth populations, highlighting how these organizations have interacted with the larger field and learned from one another to address issues of contextualization, pedagogy, sustainability, and scale. Through descriptions of programming in Rwanda, Algeria, and the Philippines, the chapter offers insight into the complexities of life skills curriculum development and contextualization processes and highlights issues that remain difficult to resolve, as well as new frontiers for programming in rapidly changing economies.
\end{abstract}

Keywords Youth employment · Workforce development · Soft skills · Life skills · Rwanda $\cdot$ Algeria $\cdot$ Philippines

C. Honeyman $(\bowtie)$

World Learning, Washington, DC, USA

e-mail: catherine.honeyman@worldlearning.org

L. Cordisco Tsai

Carr Center for Human Rights Policy, Harvard Kennedy School, Cambridge, MA, USA

e-mail: laura_cordisco_tsai@hks.harvard.edu

N. Chervin · M. Sany

Education Development Center, Waltham, MA, USA

e-mail: nchervin@edc.org; MSany@edc.org

J. Ubaldo

10ThousandWindows, Knoxville, TN, USA

e-mail: jubaldo@pticebu.org

J. DeJaeghere, E. Murphy-Graham (eds.), Life Skills Education for Youth, Young People and Learning Processes in School and Everyday Life 5,

https://doi.org/10.1007/978-3-030-85214-6_6 


\section{Acronyms}

$\begin{array}{ll}\text { 10KW } & \text { 10ThousandWindows } \\ \text { EDC } & \text { Education Development Center } \\ \text { MIFOTRA } & \text { Rwandan Ministry of Public Service and Labour } \\ \text { MEPI } & \text { US Middle East Partnership Initiative } \\ \text { MI } & \text { Motivational Interviewing } \\ \text { MOE } & \text { Ministry of Education } \\ \text { NEET } & \text { Not in Education, Employment, or Training } \\ \text { STEP } & \text { Soft Skills Training and Empowerment Program } \\ \text { TVET } & \text { Technical and Vocational Education and Training } \\ \text { USAID } & \text { United States Agency for International Development } \\ \text { WDA } & \text { Rwandan Workforce Development Agency } \\ \text { WRN } & \text { Work Ready Now }\end{array}$

\section{Introduction}

One major domain of life skills programming falls within the workforce development field, which broadly focuses on preparing people for employment or selfemployment in particular social and economic contexts (related to what Murphy-Graham \& Cohen, Chap. 2, [this volume] categorize as labor market outcomes). Workforce development programming may focus on different age groups and on a range of workforce concerns; this chapter's focus is on life skills for youth workforce programming in the international development arena.

Diverse youth workforce development actors have their own institutional perspectives on life skills-whether referred to as transferable skills, social emotional skills, soft skills, or under other names. There is growing consensus, however, that these skills play a crucial role in youth employment, entrepreneurship, and earning outcomes and should be a focus of investment in addition to the more traditional emphasis on academic, technical, and vocational skills. At the national level, workforce development actors involved in life skills education include government agencies, technical and vocational education and training (TVET) agencies, higher education institutions, non-governmental organizations (NGOs), and private sector representatives. Multilateral organizations, bilateral donors and philanthropy funders, and international nonprofit and for-profit organizations are also involved in workforce development programs in various contexts.

Approaches to life skills in these circles are shaped by a variety of factors, including funders and their priorities, exchanges among implementing organizations, research, and local concerns. This chapter focuses on how three organizations involved in youth workforce development have interacted with these different forms of influence on life skills programming, confronting questions of contextualization, pedagogy, sustainability, and scale in three very different contexts-Rwanda, Algeria, and the Philippines. In particular, we focus on donor and developed 
country institutions as powerful actors in an international field of influence that shapes programming, and the discourse of an ad hoc professional community of practice that shares ways of thinking and doing around life skills-while also showing that this international influence is tempered by efforts to adapt life skills programming for particular contexts and populations.

\section{Influences of an International Community of Practice}

The three organizations whose cases are featured in this chapter, World Learning, Education Development Center (EDC), and 10ThousandWindows (10KW), are all nonprofit organizations active in the youth workforce development field. While World Learning and EDC are both based in Washington, DC and operate various types of educational programming in multiple countries around the world, $10 \mathrm{KW}$ focuses its work specifically on survivors of human trafficking and violence in the Philippines. As organizations, we have come into contact in a variety of spaces focusing on international workforce development and life skills programming for employability_including in conferences, webinars, workshops, and email listservs. These spaces have created, both intentionally and organically, a large professional community of practice characterized by a shared interest in teaching employability skills internationally. By "community of practice" we mean the social relationships that naturally develop among people and institutions engaging in related activities, who over time develop shared ways of thinking and doing through situated learning, as described in the ethnographic work of Jean Lave and Etienne Wenger (1991). This particular ad hoc community of practice also includes many other members from the international development community.

The situated learning around employability life skills programming that takes place within this community of practice is influenced by factors of power, positionality, and command of resources (Bourdieu, 1972, 1990), as well as by research, context, and learning from experience. Major developed-country education systems and large private corporations have significant influence in this international community of practice, as life skills curricular frameworks such as Equipped for the Future, SCANS, P21, and ATC21S, reflecting the input of companies such as Apple, Microsoft, CISCO, and Intel, have been taken up as references for developing country contexts (See Stites, 2011 for more on the history of corporate frameworks and influences). Other organizations and funders, including the OECD (Kautz et al., 2014), the World Bank (2019), the World Economic Forum (2018), and the MasterCard Foundation (2017), also publish influential resources on life skills and their relationship to improving employment outcomes, carrying significant weight with practitioners due to these organizations' economic, cultural, and social capital (Bourdieu, 1986).

For many organizations implementing international youth workforce programs, the United States Agency for International Development (USAID) also plays a prime, influential role as one of the largest funders of international workforce development programming. USAID-funded workforce development projects, each 
typically 3-5 years in length, operate in some 30 countries around the world. Recent figures suggest they reach approximately 200,000 youth per year (Honeyman \& Fletcher, 2019). While this reach is still nowhere near the numbers of youth involved in government-run workforce development systems in those same countries, USAID has had an outsized influence in consolidating certain research in the life skills domain, and has shaped practice through intentional learning coordination mechanisms, ${ }^{1}$ through the assumptions set out within USAID requests for proposals, and through other means such as standardized indicators for measuring project achievements. Among other effects is USAID's adoption of the term "soft skills" for the social, emotional, cognitive, and employability skills that are the focus of the workforce development programming it funds. In contrast, USAID primarily uses the term "social-emotional learning" for basic education programs, and "life skills" for youth sexual and reproductive health-focused programs, despite significant overlap among the specific skills designated by these terms. Because this chapter is concerned with workforce development programming that has been influenced by USAID terminology, we use the term "soft skills" from this point forward (although we recognize these are broadly equivalent to "life skills" as conceived by other authors in this volume).

Some two dozen international organizations, both for-profit and non-profit, implement most of the large-scale workforce development programs funded by USAID, the US Department of Labor, and the US Department of State. ${ }^{2}$ As the research and discourse around soft skills and employability has evolved over the past two decades in the fields of psychology, education, and economics, as well as within donor discourse, these organizations have increasingly converged in their language and practices even as they have deepened and clarified their approaches to soft skills programming. The three case studies featured in this chapter illustrate that convergence while also offering insight into the complexities of soft skills curriculum development and revision processes in very different contexts and with different target populations. ${ }^{3}$

Each organization included in this chapter first developed its own institutional approach to soft skills curriculum around 2009, beginning with projects in the core national contexts featured here. A brief timeline illustrates how these organizations, and their soft skills education programming and discourse, have been tied together within the larger community of practice described previously. EDC's soft skills

\footnotetext{
${ }^{1}$ In recent years, these include the Workforce Connections project and the YouthPower initiative.

${ }^{2}$ This dominance of large international organizations may be changing due to USAID's New Partnerships Initiative, focusing on making more funding accessible to a variety of institutions and organizations around the world.

${ }^{3}$ As co-authors of this chapter, we each had a particular role in one of the case studies described. Catherine Honeyman wrote the overall chapter framing and the World Learning Algeria case study, drawing on her experience as technical advisor for the project. Nancy Chervin wrote the EDC Rwanda Case study in collaboration with Melanie Sany, who managed the EDC projects in Rwanda. Laura Cordisco Tsai wrote the $10 \mathrm{KW}$ case study in collaboration with Janice Ubaldo, drawing on their involvement in the organization's curriculum development and research processes.
} 
approach, first developed for Rwanda in 2009 and initially based on US and OECD curricular frameworks, became one of the sources consulted in a pivotal USAIDfunded publication "Key 'soft skills' that foster youth workforce success: Toward a consensus across fields" (Lippman et al., 2015). Featuring an extensive international literature review, that publication aimed to determine the skills with greatest international research evidence of impact on four types of workforce outcomesemployment, promotion, income, and entrepreneurial success—as well as the skills with evidence of malleability during the youth years. The report ultimately recommended that programs focus on five soft skills: positive self-concept, self-control, social skills, communication, and higher-order thinking skills. Subsequently, USAID funded a literature review on effective pedagogical methods for soft skills development, which also drew on EDC approaches among a range of other models (Soares et al., 2017). USAID circulated these publications widely and referred to them in requests for proposals, ensuring that they became well-known among the organizations implementing workforce development programs internationally.

Meanwhile, World Learning and 10KW had also developed their own approaches to soft skills programming around 2009, drawing on a combination of US and international influences (Algeria and the Philippines, respectively). In 2017, after many years of program implementation, World Learning consulted the USAID publications above, as well as other research sources, to create guidance for its own soft skills curriculum revision process globally. World Learning also shared this guidance and a set of curriculum development tools externally in industry-specific conferences and other settings. It was in one such conference that 10KW, EDC, and World Learning staff came together and began exchanging experiences around their soft skills curricula and programming, with $10 \mathrm{KW}$ subsequently using the World Learning tools for its own process of curricular revision.

Our conversations and experiences as technical advisors of organizations implementing soft skills programming for workforce development within this international community of practice have brought to the fore three major issues in developing our programs: contextualizing the focus of soft skills programming, determining and training for effective pedagogical approaches, and sustaining and scaling up these initiatives.

\section{Contextualization}

In the midst of a movement towards more uniform global recommendations for soft skills development, and despite a certain homogenizing influence from institutions such as USAID and the OECD as described previously, international development program implementers continue to recognize the key importance of having contextually relevant curricula that evolve based on experience with particular

\footnotetext{
${ }^{4}$ The Global Youth Economic Opportunities Summit, 2018.
} 
populations. The cases in this chapter show how implementing organizations must both respond to the expectations of funders and report on standardized indicators, and also dialogue with and respond to important local actors, including government agencies, training institutions, and youth themselves.

\section{Pedagogy}

While the past decade has featured demonstrably greater consensus around the importance of teaching particular soft skills, how to do so effectively is another matter. The authors' experience with mainstream competency-based curriculum development processes around the world shows that education institutions often end up neglecting the non-academic skills and "attitudes" aspect of their curriculum development frameworks as they progress from initial outlines towards more detailed curricula, pedagogical recommendations, and learning materials (see Honeyman, 2016). In great part, this may be because the methods for developing soft skills are not well known or understood. The cases in this chapter therefore document our pedagogical approaches for developing these skills.

\section{Sustainability and Scale}

Another significant challenge that implementers of soft skills development programming face is the question of how to institutionalize effective curricula into a broader system capable of reaching much larger populations, or deepen it to achieve sustainable change for target populations over time. Research by the MasterCard Foundation (Ignatowski, 2017) examined three soft skills development programs in Sub-Saharan Africa that have achieved larger scale, identifying six key drivers: an enabling policy environment, evidence of impact on youth outcomes, strong political champions, wide stakeholder engagement, decentralization of authority, and flexible funding. This chapter's cases illustrate the importance of these factors and make clear that the dominant short-term project-based mode of the major funders of soft skills and workforce development programming poses a significant obstacle to sustaining and scaling up such programming, ultimately limiting the chances for many youth to develop these skills despite the significant resources invested for that purpose.

The case studies that follow focus on illustrating how the three aspects of soft skills curriculum development addressed above-contextualization, pedagogy, and sustainability and scale ${ }^{5}$ - have played out in three very different contexts: Rwanda,

\footnotetext{
${ }^{5} \mathrm{~A}$ fourth question-how to measure these skills-is beyond the scope of what this chapter can cover in detail, particularly considering the burgeoning work in this area.
} 
Algeria, and the Philippines. A concluding section following the case studies highlights common challenges with soft skills curriculum development processes, as well as discussing the new frontiers that are now emerging in the teaching of soft skills for labor market outcomes.

\section{Rwanda: Work Ready Now (Education Development Center) ${ }^{6}$}

\section{Country Context}

Since 2009, Education Development Center has been leading youth programs in Rwanda with funding from USAID and the MasterCard Foundation. EDC's local team and partners provide youth with the skills to continue their education, find employment, or start their own businesses. Rwanda is a youthful country: $50 \%$ of the population is below 20 years old. Despite impressive economic growth in the past decade, the national poverty rate is 39\%; among youth, however, it is $70 \%$ (with $55 \%$ in extreme poverty). In $2018,31 \%$ of youth were not engaged in education, employment or training, and 65\% were underemployed (World Bank, 2020). Youth are disproportionately located in - and migrating to-urban areas, where youth unemployment is three times that of rural areas (YouthStart, 2016). Each year, 125,000 first-time job seekers enter the labor market, a number which the economy is unable to absorb, so only a handful gain access to the formal sector (YouthStart, 2016). As a result, most youth work in the informal sector.

Over the last decade, there has been a consistent, clear vision to propel Rwanda into middle-income status, which includes significant changes to the workforce development system. One of the main targets has been to create roughly 200,000 non-farming jobs per year, which has motivated action across national ministries. The government has also emphasized the role of TVET in reaching its economic goals, aiming to increase the number of lower secondary school students entering TVET from $21 \%$ in 2017 to $60 \%$ by 2024 . Nonetheless, when EDC began our work in Rwanda in 2008 with the USAID Akazi Kanoze project focusing on out-ofschool youth between the ages of 14 and 24, we found that there was:

- No curriculum informed by employer demand, nor localized labor market assessments

- No incorporation of soft skills into the secondary school curriculum

- Little to no use of hands-on, learner-centered pedagogical approaches.

In response to these gaps, we developed an approach that included work readiness training for youth. In close partnership with the Rwandan government, our

\footnotetext{
${ }^{6}$ Information provided for this case study was primarily collected in the form of practitioner reflections. It also includes reference to an experimental study with randomly assigned treatment and control groups, which was approved by EDC's ethics review board.
} 
strategy grew organically as we adapted our work readiness curriculum to various youth populations. As the approach gained more interest from the government, demands to expand the program beyond out-of-school youth to those in the TVET and formal education systems increased, enabling us to work with the government and local organizations in adapting and incorporating our training into existing systems.

\section{Contextualization}

Our original program design, responding to USAID-required activities, proposed a model that networked out-of-school youth with business opportunities through local NGOs. As we grappled with the question of how these NGOs could better prepare youth for jobs, the idea of a work readiness curriculum emerged, focusing on building the soft skills and competencies youth need for their first entry-level jobs or to run their own small businesses. At the time, little detailed information existed in the international development space about curricula that met these requirements, so we began by developing a curriculum framework that defined the key content areas for a comprehensive skill development program with an emphasis on livelihoods and work. The curriculum framework initially drew from the Equipped for the Future standards, developed for adult learners in the United States, and which was externally evaluated in 2011 to ensure alignment with three internationally recognized work readiness frameworks: SCANS, P21, and ATC21S (Stites, 2011). In 2015, we also analyzed how the Big Five Personality Factors (see Murphy-Graham \& Cohen, Chap. 2, this volume) were addressed because these categories of noncognitive skills are related to success in both school and the workplace. The Big Five are increasingly viewed as important for a variety of uses in workforce development: selection, training, outcomes assessment, professional development, and international comparisons (Roberts et al., 2015). In 2013, EDC and Professional Examination Services developed a learner assessment using situational judgement questions based on the Big Five Personality Factors and Work Ready Now (WRN) modules. It is important to note that the WRN framework was developed 5 years before USAID conducted its review of soft skills frameworks and skill areas, described in the previous section. Our framework was later included in, and seems to have significantly shaped, this research.

This framework served as a starting point for developing the curriculum in Rwanda, later becoming EDC's global Work Ready Now (WRN) curriculum. A curriculum framework, the scaffold upon which a full curriculum is built, defines the skills, knowledge, and behaviors that are to be taught and learned. EDC's WRN framework covers intrapersonal and interpersonal skills, including skills that are used in a variety of settings and not just work (such as goal-setting and communication), employability skills (such as workplace behaviors), and critical thinking skills (such as evaluation of appropriate strategies). Illustrative teaching and learning activities accompany each skill. 
After a review of the framework in Rwanda, modules were drafted by a mix of Rwanda- and US-based technical advisors. Next, a series of curriculum development and revision workshops took place. A group of Rwandan NGO partners, facilitators, and business representatives as well as staff from the Rwandan Ministry of Public Service and Labour (MIFOTRA) and the Workforce Development Agency (WDA) reviewed the modules. They also provided feedback regarding the content, language, methodology, context, and cultural appropriateness. This process resulted in deleting, changing, and adding activities, particularly to align with Rwanda's skills development priorities in customer care and entrepreneurship.

The resulting Rwandan curriculum consisted of eight modules, with materials for $120 \mathrm{~h}$ of instruction, as depicted in Fig. 6.1.

These modules include personal development, communication, finding and keeping work, leadership, health and safety, workers' rights and responsibilities, financial fitness, and an introduction to entrepreneurship. Overall, the modules seek

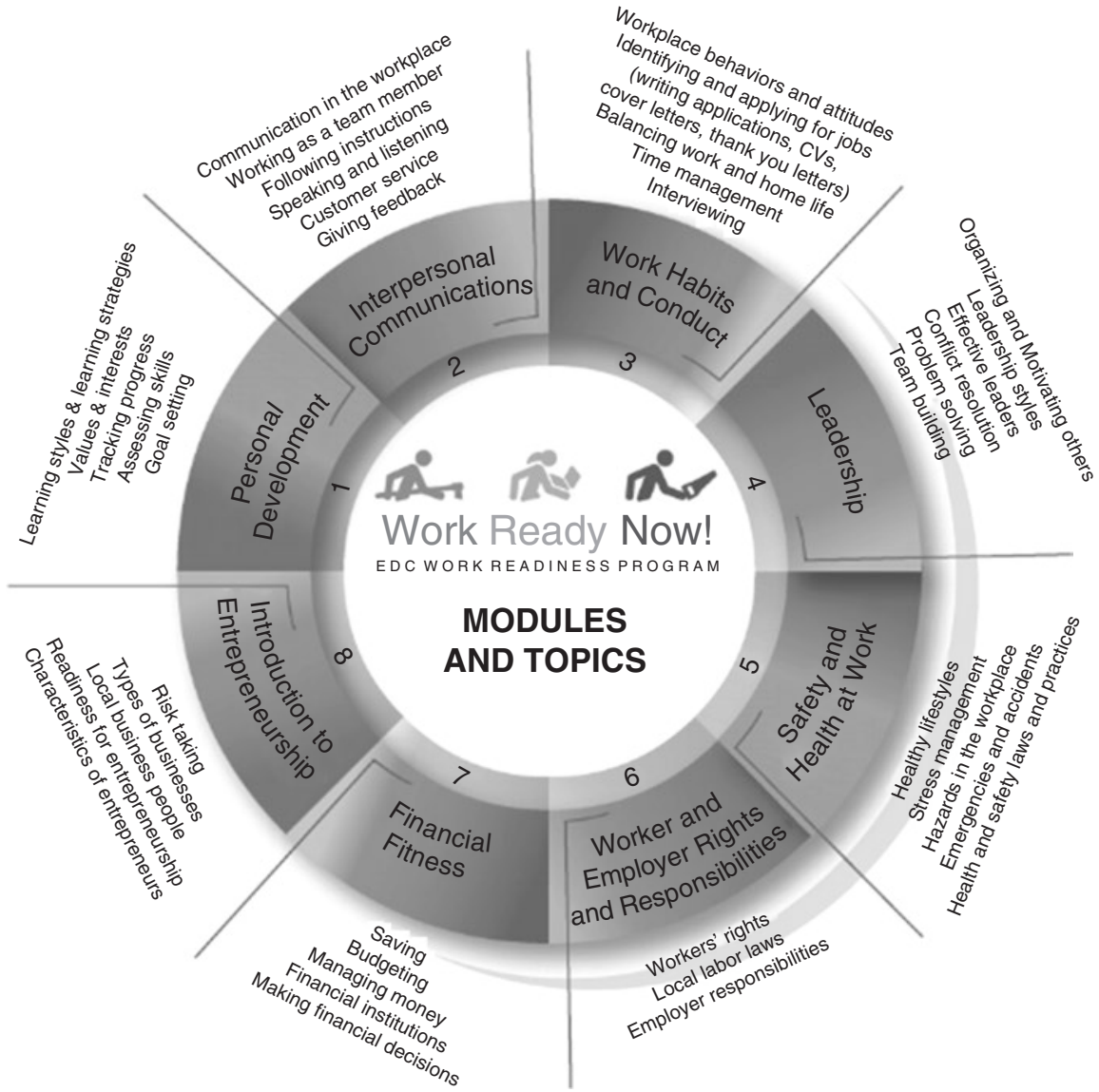

Fig. 6.1 Work Ready Now modules and topics 
to develop a large number of specific soft skills, including: self-reflection, assessing, goal-setting, taking initiative, communication (listening and speaking in the workplace, giving presentations, giving and receiving instructions and feedback), social skills (cooperating, working in a team, providing good customer service), cognitive skills (finding and analyzing information, reading for information, decision-making, and problem-solving), behaving appropriately at work, planning skills (managing time, managing home and work life, tracking personal progress), and leadership, among others.

The original intention was that other countries could develop their own curriculum using the WRN framework. Though the curriculum development process proved to be time-intensive, taking almost a year in Rwanda, we found that the resulting curriculum and materials were easily adaptable for other contexts and that it would not be necessary for every country to start from scratch. We have been able to adapt versions of the Rwandan WRN curriculum to new countries according to youth levels of education and socioeconomic situations. Key players adapt WRN to the local cultural and economic context during a workshop, which brings together youth-serving organizations, government officials, instructors, and the private sector. A local adaptation will pinpoint issues such as needing to prepare youth for communicating with people from other cultures, identifying the specific finance service providers in a country, or localizing job seeking processes such as the use of virtual interviews and networking sites like LinkedIn which vary from country to country. Furthermore, the majority of scenarios, work-based situations, and role models come from examples from the country of adaptation. We developed a WRN implementation toolkit to formalize this adaptation process. This toolkit helped to maintain consistency and quality as we contextualized WRN for 26 countries in the last 10 years.

\section{Pedagogy}

The WRN curriculum developed first in Rwanda uses techniques such as group activities, role-plays, large- and small-group discussions, and personal reflection. Youth practice customer service interactions in role plays, simulate doing a complex office move to learn about cooperating as a team, and map out their goals as they create professional development plans. Like the World Learning and 10KW programs described below, youth also develop career portfolios comprised of items they will use for job seeking, and wraparound activities such as workplace exposure to complement the training outside of the classroom. Work exposure includes observations, informational interviews, and job shadowing assignments that require the youth to identify workplaces and build relationships with employees at local businesses. After completion of the WRN training, Rwandan youth enter an accompaniment phase of the program where they continue to do observations and conduct informational interviews as they seek employment or begin their own business. 
Our experience in Rwanda demonstrated that for implementation to be successful, the content and pedagogy must be maintained, and sufficient teacher training provided. WRN's participatory learner-centered approach is intentionally outlined in very detailed steps. It is designed for use by both less experienced facilitators and instructors who may be accustomed to more traditional approaches. We found that, on the one hand, an NGO facilitator may be youthful and energetic and take naturally to the activities but have minimal prior facilitation experience. On the other hand, a Rwandan schoolteacher may have taught for 20 years, but mainly through lecture format. Both groups appreciate that the steps walk them through what they say and do all along the way.

The training of trainer's approach emphasizes mastering the content and pedagogy. Trainings are slowly paced, with a day spent on each module. The first training of trainers workshops in Rwanda averaged 10 days in total (split into two workshops, covering different modules, with the second workshop including reflection on their teaching so far). Each trainer gains a background in adult learning, experiences learner-centered instruction, and leads at least two teaching demonstrations. They receive structured feedback both during the training and while implementing the curriculum. Teachers tend to be enthusiastic adopters of the curriculum. While teachers in Rwanda had received professional development in learnercentered approaches as part of the formal school system, many have remarked that it was the WRN training that helped them finally grasp this approach. Practicing the delivery of activities during the training and using the methods in the curriculum with youth in their classrooms helped them to internalize learner-centered, participatory approaches. Class size needed to be considered carefully, however. The curriculum was originally designed for a trainer and assistant to lead a class of 25 youth. In the Rwandan school system, the ratio was often one teacher to up to 50 youth in a class. Activities were rethought so they could still be participatory within this constraint.

\section{Sustainability and Scale}

Today, these practices, particularly the pedagogy underlying the WRN approach and the use of the WRN curriculum itself, are widespread among a number of private and public service providers including public technical and vocational education and training (TVET) and formal education institutions. By including local stakeholders in the development process, they took ownership of the curriculum and promoted it in their institutions. For instance, following the first Rwandan curriculum revision workshop described above, the Ministry of Public Service and Labour requested that we provide training to several hundred youth. Ultimately, we trained and mentored over 200 trainers from private institutions, as well as over 700 school directors, master trainers, and teachers from public TVET and secondary schools. This learner-centered soft skills training reached over 200,000 in-school youth and 60,000 out-of-school youth. 
While the soft skills program in Rwanda began with USAID-defined objectives and funding, it soon evolved beyond that frame towards institutionalization into permanent Rwandan structures and policies. Our work with out-of-school youth sparked interest from the Rwandan Ministry of Education, who in turn asked that we adapt WRN for the formal education system. This request took place in the midst of an education reform process that moved the system to a competency-based approach. Given WRN's standards-based framework, it was a good match. The inschool adaptation in Rwanda took place alongside national reforms in two types of schools: TVET and general secondary.

For TVET, there was an existing effort with the government's Workforce Development Agency to develop competency-based curricula in the national system. EDC plugged into that effort by mapping WRN content throughout the school year in each of the technical curricula. WRN aligned with the TVET qualification's required complementary competencies, which include employability and life skills that are applicable to all occupations. At the same time, the local EDC team advocated for work readiness skills to be taught through the entire TVET system. The life skills curriculum was then validated and mandated as Level 3 under the TVET qualification framework. EDC worked with the WDA to merge its eight modules into five courses that included dedicated time for our activities. Minor adjustments were made to the terminology of the WRN training manual so it aligned with their curriculum. For example, WRN's Personal Development module was integrated in their "Occupational and Learning Process" course.

For general secondary education, the government had started aligning the entire secondary curriculum to a competency-based approach, and it became clear that WRN could address some needs during this alignment. Through a comprehensive design process, we worked with the Ministry of Education (MOE) to embed WRN into their entrepreneurship instruction at all levels of lower and upper secondary. We participated in the competency-based curriculum reform process led by the Rwanda Education Board to help the entrepreneurship team integrate the curriculum. The team closely compared the existing materials with ours, developed a syllabus, and identified when WRN activities would be used by teachers in their units. Other than aligning terminologies, no major changes were required. The biggest challenge was deciding how to spread out the work readiness curriculum modules across the grade levels without losing continuity. We addressed this challenge by repeating essential topics within modules across the years. For example, goal setting and planning repeats itself over the years as learners' interests and skills develop and change.

Because the WRN soft skills content is embedded into a national curriculum, it is not something "extra" for the teachers to do, but rather helps by providing them with high quality content that addresses the skills they need to teach. A true collaboration with the MOE enables us not only to align the competencies and the skills prioritized by the government of Rwanda and WRN, but also to influence the broader curriculum reform through WRN pedagogy and approach. In this shift to a competency-based approach, teachers were going to be required to teach differently - in a more participatory and less didactic way. WRN provided a model of how to implement a competency-based curriculum. 
While adapting the curriculum to an in-school program, several considerations had to be addressed. First, for both school systems, careful consideration was taken to align the WRN competencies with the government's own competency framework. In that process we helped the Rwandan Education Board integrate the content and methodology into entrepreneurship for secondary schools and we helped WDA integrate WRN into their core competencies in vocational schools.

Second, the flow and scaffolding of the competencies was considered carefully as the modules would be taught by different teachers at different levels. We needed to determine how the skills and activities in each module would be distributed across levels and subjects, ensuring that foundational knowledge and skills that feed into subsequent topics in the WRN curriculum were introduced before the more complicated topics. For instance, identifying one's values, interests, and skills feeds into the next step of goal setting and writing a professional development plan. In Rwanda, this instruction was taught across all 6 years of secondary school but within one subject (entrepreneurship). Experience has shown that it is better to integrate the curriculum into as few subjects and levels as feasible in order to keep the WRN training as intact and compact as possible, so as to encourage youth to build selfconfidence and comfort with their group. Facilitators also become familiar with the strengths and areas for growth among the youth. When it is not possible to keep it intact, it is helpful to have a week, at the end of the school year, when the students all come together at a given time to review key lessons.

Third, we found that it is important to identify the teachers, their availability, and who will train them. These could be local implementing partners or the inspectors in the system responsible for teacher training. In Rwanda, the capacity of Rwanda Polytechnic officials is now being developed to be responsible for teacher training for the TVET level 2 programs.

Finally, there are considerations to be made beyond the content and methodologies when integrating into schools and institutionalizing training materials into a school system. Adjustments may need to be made to the activity lengths (to fit within classes of 40 or 45 min length instead of 1-2 h sessions), to the materials used so that they are affordable (for ministries who purchase classroom supplies and parents who purchase the school books), and to the assessments (to ensure that the soft skills assessment can be used nationwide across all schools and in a format that can be administered by teachers in a classroom).

To make this range of work possible over multiple years, EDC competed for additional funding under multiple projects and donors. Without piecing together resources over a longer period of time, this depth of institutionalization and influence on the Rwandan educational system would not have been possible within a single project's implementation timeframe.

Our research indicates that the route that we have taken - focusing on this particular content and pedagogy, while using a systems-strengthening approach - is meeting the needs of youth, employers, and educators. For out-of-school youth, $66 \%$ of program graduates have found employment or started an income-generating activity within 6 months of graduation. Ninety-seven percent met or exceeded employer expectations. In regard to in-school youth, youth in the program had 
larger gains in work readiness knowledge and key competencies than their peers. Participants were more likely to be employed after completing the program than those who did not participate (Alcid \& Martin, 2017).

One of our key lessons learned was the extent of our curriculum's adaptability. Two primary factors stand out: firstly, that a detailed curriculum framework guided its development. Secondly, it was vetted locally at all stages, from the framework development to the original adaptation and all subsequent adaptations. In the 10 years since we first developed the curriculum, technology has quickly changed the nature of the workplace. Yet the curriculum stands the test of time. It emphasizes skills such as adaptability, willingness to be a lifelong learner, and diligence-all of which are cited as key skills by employers globally. In today's COVID-impacted world, we are exploring how to use technology for teacher training and delivery to youth without compromising quality and the value of face-to-face interaction.

\section{Algeria: WorkLinks (World Learning) ${ }^{7}$}

\section{Country Context}

World Learning has worked in Algeria since 2005, and we began workforce development-related programming in 2010 with support from the US State Department, later including private funders such as HSBC Bank and Anadarko Petroleum. In large part due to funder priorities, our focus in these projects has been quite different from EDC's initial emphasis on out-of-school youth, described in the previous case study. In Algeria, we work primarily with the country's large population of unemployed but educated youth with at least a high school diploma, and often a university or even post-graduate degree. Data on youth unemployment rates in Algeria varies widely. Even before the COVID-19 crisis, one study suggested that at least $39 \%$ of university graduates remain unemployed even three years after graduation (CREAD and ILO, 2017); official statistics-last reported in 2018 before a wave of protests that has continued to the present-documented overall youth unemployment at $29.1 \%$ (ONS, 2018). Algeria is considered an upper middle income country, but with a stalled economy that is nearly completely dependent on petroleum, accounting for over $94 \%$ of the country's export revenue and making the country extremely vulnerable to external oil price shocks. ${ }^{8}$ In this context, our youth workforce development projects have focused primarily on improving youth integration into formal employment positions in a variety of industries, including

\footnotetext{
${ }^{7}$ This case study is primarily based on practitioner reflections and routine analysis of project monitoring and evaluation data collected as part of an educational process. It also includes reference to qualitative research approved by World Learning's School for International Training IRB (IORG \# 0004408).

${ }^{8}$ Observatory of Economic Complexity: Algeria Country Profile https://oec.world/en/profile/ country/dza/
} 
petroleum, plastics, construction materials, pharmaceuticals, IT, education and training, and more - across 12 Algerian governorates ranging from the highly-populated cities on the Mediterranean coast to desert regions in the south.

\section{Contextualization}

Since 2010, our approach to employability and soft skills training has evolved considerably, responding to local context, donor priorities, and implementation realities, as well as efforts to more deliberately incorporate research on effective soft skills instruction. World Learning's Algerian education specialists, specifically trained in experiential learning pedagogy (Kolb, 1984), began initially with a small set of core courses that we developed to meet the needs of a new career center at the University of Ouargla, following some informal employer outreach and observation of students' skills gaps in seeking employment. The modules, typically lasting $2 \mathrm{~h}$ each, included personal skills and interest assessments, writing customized CVs and cover letters, practicing interview skills, and learning about job search techniques. They did not overtly reference other soft skills, but they employed an experiential learning methodology used in all of World Learning's global programs, which formally or informally employs cycles of experience, reflection, conceptualization, and further experimentation, designed to foster the development of communication, social skills, and critical thinking. For subsequent projects starting in 2012 and 2015 with university and TVET career centers in other parts of the country, field staff reflected on a key obstacle young people faced in Algeria - the lack of work experience-and sought to encourage volunteering as a means for overcoming this barrier, as well as for encouraging broader civic engagement and fostering increased engagement of youth with disabilities and other barriers to workforce participation. This team revised the curriculum accordingly, introducing new modules on leadership, overcoming individual and collective obstacles, volunteering to gain work experience, and action planning. This revised version continued focusing on communication and social skills, and added a focus on additional soft skills such as goal-orientation, planning, problem-solving, and teaching the value of social inclusion.

In 2017, we decided to re-examine this soft skills curriculum again for two reasons. First, with the publication of the USAID-funded literature reviews described in the introduction, it was clear that the research base around soft skills had developed to the point that it could inform our curriculum development and implementation more clearly than before. And second, we had conducted an initial tracer study of 678 program participants, which did not show the clear correlation that we had expected between completion of the soft skills courses and improved employment outcomes. While the data showed that youth who took our soft skills courses were 
significantly less likely to be in the inactive NEET $^{9}$ (Not in Education, Employment, or Training) category than their peers who did not take our courses, that difference was largely due to furthering their studies rather than increased rates of employment. This data was non-experimental and so could not determine the direction of causality; additionally, the choice to pursue further studies could reflect one success of the soft skills courses in helping youth evaluate their own skills in relation to market opportunities, determining that they needed some further education/training to find employment. Nevertheless, these findings also suggested a need to reexamine the curriculum, to ensure that it was actually teaching the skills youth most needed in order to find employment in the Algerian context.

Anticipating that this question would affect not only our work in Algeria, but also around the world, we began first by cataloguing all the international research we could find regarding the range of soft skills we should consider to improve youth employment outcomes. We also convened World Learning staff implementing a variety of types of youth programs in different countries to discuss how they selected the soft skills to focus on in a particular context, how they developed curriculum frameworks, what they found to be the most effective pedagogical practices, and how they evaluated instructor pedagogy and student achievements. This process resulted in a set of practitioner-oriented curriculum development tools in a publication titled Soft Skills Development: Guiding Notes for Project and Curriculum Design and Evaluation (Honeyman, 2018). These tools included: an inventory of 44 soft skills terms and clusters found in the research we consulted, to aid curriculum designers in making more conscious and specific choices around which skills they intended to build; a checklist of pedagogical practices found to be effective in the research we consulted and in World Learning experience; an example pedagogical observation form for assessing current instructor practices; guidance on creating psychometric or observation-based soft skills assessments; an example observation rubric for assessing student skills; and curriculum framework planning guides for specific skills and for a cluster of skills, among other resources. This toolkit was intended to help World Learning staff design and implement a variety of youth programs around the world in an explicitly context-responsive way.

We next searched for context-specific information on the soft skills needs of youth in Algeria. However, we quickly found that the little information that was available struggled with vague terminology and a lack of clarity in skills definitions, making it difficult to know precisely which skills to teach. With support from the US Middle East Partnership Initiative (MEPI), we therefore designed and undertook qualitative research in Algeria to examine specific contextual needs for soft skills, as well as examine what the existing soft skills courses were achieving and where there may be gaps (Honeyman, 2019). This research included re-analyzing qualitative interview data with 140 employers and other stakeholders from nine local labor

\footnotetext{
${ }^{9}$ NEET statistics measure youth who are Not in Education, Employment, or Training-a complementary measure of youth inactivity beyond just the youth unemployment rate, which focuses only on those who are searching for work but have not been able to obtain it. Algeria's NEET rate in 2018 was $28.3 \%$ (21.3\% for young men and $35.8 \%$ for young women) (ONS, 2018).
} 
market assessments we had conducted (Farrand, 2019). It also involved new individual questionnaires and focus group discussions with stratified groups of 90 Algerian youth beneficiaries of our program-male and female, employed and unemployed-in six governorates. We asked youth to describe personal weaknesses that had hindered them in their job search, as well as contextual obstacles they faced, and they shared their own theories regarding the major differences between youth who had and had not succeeded in finding employment.

Not all the obstacles that youth face can be resolved with soft skills training. Youth spoke about several challenges that could only be significantly impacted through policy and institutional changes. For example, youth mentioned the few job openings in the fields emphasized by their university degrees (fields youth often felt they had not chosen for themselves), challenges with residency regulations and distance to jobs, delays due to public employment agency procedures, nepotism, low pay rates and indefinitely keeping youth in government subsidized "internship" positions, military service restrictions, and gender discrimination against both men and women in particular types of jobs.

Nevertheless, youth did also identify internal factors akin to soft skills that they felt hindered their job search even if the above issues were to be addressed. Employed and unemployed, male and female youth made comments like the following when trying to explain why some youth found jobs and others did not: "It depends on the level of motivation of the person. If you are a motivated person, you won't stop looking" (unemployed female), and "It all comes down to persistenceyou have to be proactive during the search, you have to be aware of the job openings. Otherwise there is no way it is going to work" (employed male).

The youth also spoke about the importance of adaptability, and young women in particular cited this as an obstacle that they believed prevented many young men from accepting a job at a lower level than they had hoped for, or in a different field from their training. Finally, both young men and young women mentioned their need to develop skills for managing emotions, particularly stress - and young women particularly emphasized the relationship between stress management and learning planning and time management skills to balance their many daily tasks in their household, studies, and search for work. The research also re-confirmed the importance of teaching several functional job search skills: career planning, employing diverse job search strategies, building customized CVs and online profiles, and interviewing.

Overall, the research concluded that there were 12 essential soft skills for Algerian youth to obtain employment, which we divided into three domains, similar to the domains in the original definition of life skills by UNICEF (2012) (Honeyman, 2019):

- Intrapersonal: positive self-concept, self-motivation, perseverance, adaptability, managing emotions (particularly stress), goal-orientation, conscientiousness or being hardworking

- Interpersonal: social skills (combining building relationships with others and managing conflict), communication skills (combining oral, written, nonverbal, listening), and professionalism (as defined by Algerian employers, including self-presentation and etiquette) 
- Cognitive skills: Thinking skills (learning from experience, seeking information, critical thinking, and problem-solving), and planning and time management

The team noted that while many of these skills overlapped with core USAID recommendations made in the publications mentioned earlier in this chapter-for example, youth spoke particularly passionately about the importance of the USAID-highlighted skills of positive self-concept and communication skills-some key skills were distinct. In particular, the skills of self-motivation, perseverance, adaptability, and managing emotions stood out as crucial in Algerian youth and employers' comments, although these were given less emphasis in the USAID literature review.

Based on these research findings, we revised our curriculum to be used in upcoming projects in Algeria, and included a set of procedures for adapting it to new contexts and projects, using baseline research with youth and employers. In total, the new courses-intended for youth aged 18-29 in contexts where both self-employment and formal employment are possibilities-offer up to 70 contact hours of experiential and learner-centered activities, with options for reducing the course length when necessary (see Fig. 6.2). The course modules focus

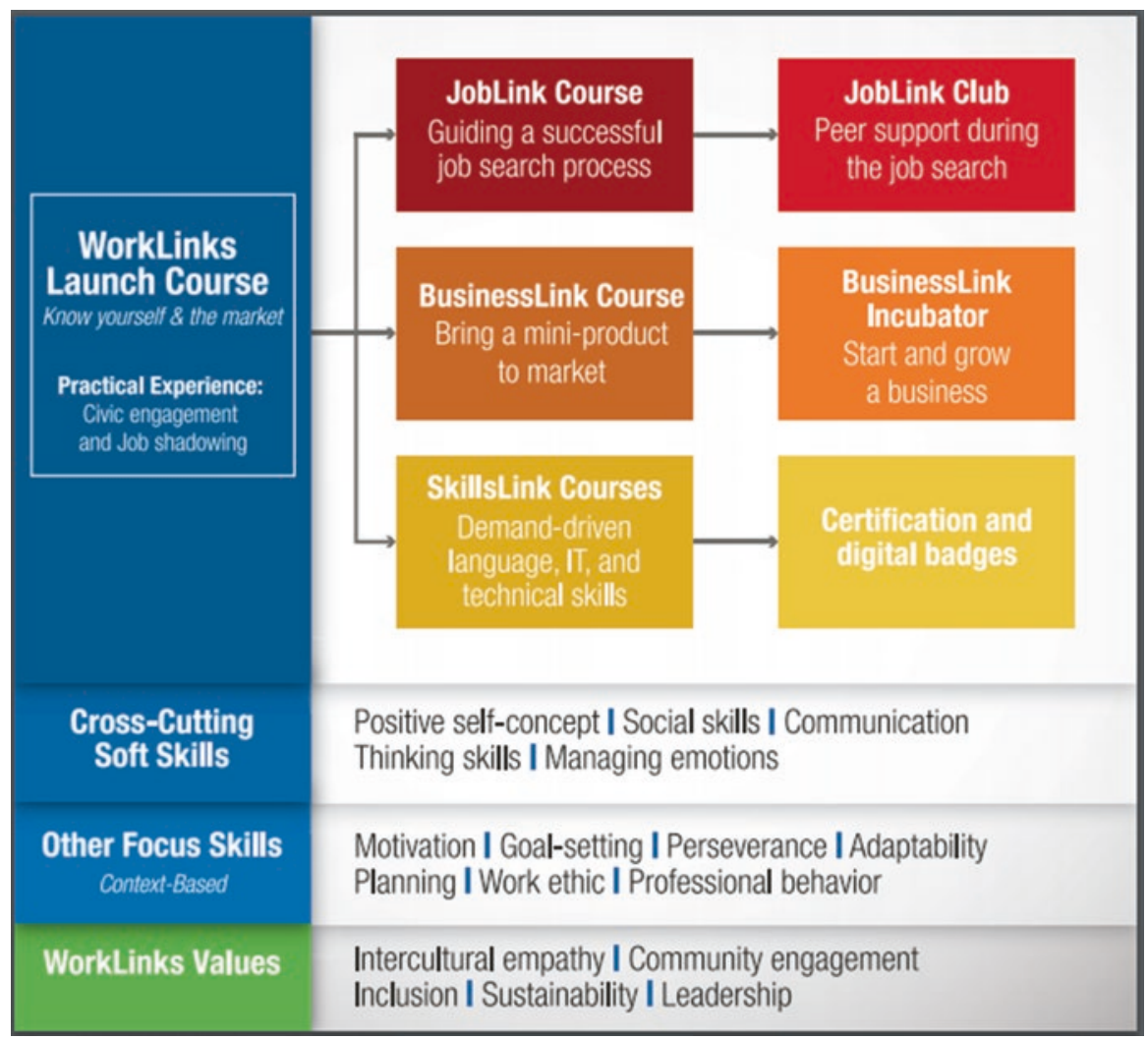

Fig. 6.2 World Learning's WorkLinks curriculum summary 
on two areas: (1) career exploration (WorkLinks Launch: Know your purpose, Know yourself, Know the market, Know the workplace, and Know your next steps) and (2) the job search process (JobLink: Your job launch plan, Personal branding online and the CV, Professional writing, Professional communication and interviews, Workplace problem-solving, and Overcoming obstacles). Youth who demonstrate entrepreneurial aptitude and interest during the WorkLinks Launch course are directed to our separate business incubation process. Finally, youth who determine they need to further develop specific technical, vocational, or professional skills are directed to a range of other offerings, depending on program design.

We also chose to integrate World Learning's four core institutional values throughout the curriculum-intercultural empathy, community engagement and leadership, inclusion, and sustainability. In this way, the curriculum reflects both our global mission as an institution, and the particular contextual challenges we identified among youth in Algeria.

\section{Pedagogy}

The above qualitative research also reconfirmed that the existing experiential learning and student-centered pedagogy of World Learning's curriculum was already highly effective, according to youth themselves, at developing three specific soft skills: positive self-concept, communication, and social skills. Many participants also spontaneously described improvements in their self-motivation and goalsetting. One young man remarked, for example:

Exchange with other students of the career center was amazing. People have taught me how to talk, when to talk, and that you don't have to talk all the time. The diversity of educational backgrounds was very enriching. Others added value from their own experiences. [...]. I developed my social skills and widened my network.

The instructional experiences that our Algerian youth beneficiaries highlighted as most useful to them were: experiential learning, group work, relationship-building and interaction with peers, group discussions, group presentations, and exposure to diversity and the concept that diverse talents and ways of being have value to the world. As a result of these research findings, we decided to retain much of our core pedagogical approach in the new curriculum.

We did, however, incorporate certain new pedagogical principles as well. First, we made a key pedagogical decision to fully integrate the 12 focal soft skills within modules focused on the more familiar processes of career exploration and the job search, rather than having separate soft skills modules each addressing, for example, communication, goal-setting, or adaptability. This decision arose out of World Learning's experience that most youth project participants are primarily interested in and motivated by learning the concrete functional skills they need to get a job (such as creating a CV or networking) and may not recognize initially the important 
role that soft skills play in the employment search process. Instead, we teach the importance of these skills gradually, beginning with our first module, which helps participants define a broader sense of purpose for themselves in participating in the course and prompts them to map out the linkages between achieving that purpose and developing certain soft skills. At the same time, World Learning decided that integration would also improve the effectiveness of the training experience, given that soft skills need to be learned and practiced in the context of achieving other tasks, rather than each in isolation. To ensure that the soft skills do not get lost in this integrated approach and to build the linguistic and cognitive structures that have an important-if not determinant-influence on behavior (Gumperz \& Levinson, 1996), in the reflection phase of the experiential learning cycle, we guide youth to identify a soft skill they have just put into practice during a curriculum exercise, we provide a definition and foster discussion about the skill, and finally we encourage them to hang each skill term up on a Skill Wall where they can continue to see and refer to it when it is raised in a cyclical fashion in later course activities. For example, when we ask participants to analyze information about their own job market through a review of job board data and through informational interviews, they reflect on how they have used higher-order thinking skills through an independent search for information and critical examining what they have learned.

The new curriculum also adds more explicit emphasis on several other pedagogical principles highlighted in our soft skills curriculum development toolkit (See Table 6.1). For example, we develop a supportive environment by having a more organized "classroom constitution" process than previously, as well as by building in an emphasis on World Learning's core organizational values of intercultural understanding and empathy, and social inclusion and justice. Consistent

Table 6.1 Expanded list of pedagogical principles for effective soft skills development

Pedagogical principles for soft skills development

1. Develop a safe, caring, and supportive environment that allows participants to express themselves and take on challenges -including the risk of mistakes-without fear of ridicule.

2. Respect principles of adult learning: Participants have a lifetime of experience to draw on: they are not blank slates; and learning must be relevant to their lives to elicit full participation.

3. Build underlying skills of social awareness to help participants identify, evaluate, andwhere appropriate- follow the norms and standards of particular social contexts.

4. Explicitly discuss what each soft skill is, why it is important, and what it looks like in practice. Define new concepts. Point out specific soft skills when they are enacted or observed in action.

5. Connect it all together into an overarching framework of principle and purpose that helps participants understand the larger picture of why developing these skills is important, and helps them apply principles to make decisions in new situations.

6. Promote skills development through experiential learning in cycles of concrete action, reflective analysis, relating the experience to abstract concepts, and planning for further action-including both prearranged exercises and demanding but achievable real-life experiences.

7. Draw on the arts, movement, and inspiring words to get participants thinking and acting in new ways. Options include theater, poetry and proverbs, painting murals, photography, digital storytelling, crafting, music, dance, sports, and more. 
Table 6.1 (continued)

Pedagogical principles for soft skills development

8. Provide consistent positive feedback when participants demonstrate core soft skills. Consider employing negative consequences when necessary.

9. Promote integration across the different learning contexts to which participants are exposed—family, community, education institution, workplace, etc—-with clear and consistent standards.

10. Ensure that staff model in their own daily life the soft skills being promoted. Support staff in recognizing and addressing any personal areas for improvement.

11. Promote strong mentorship relationships among participants or between those who are more experience and less experienced (such as adults to youth), which are meaningful and caring, and in which participants are seen as valued contributors.

12. Allow for the development of soft skills over time and in a variety of situations, not just in single lessons. Employ multiple experiential learning cycles of action and reflection.

Adapted from: Honeyman (2018) and drawing on Soares et al. (2017)

constructive feedback to reinforce soft skills development is incorporated through regular classroom constitution and professionalism evaluations, involving both student self-assessment and an instructor pre/post assessment based on observation. Participants build a portfolio as the course progresses and maintain an evolving action plan, helping them see their own progress and gather useful materials. We build underlying skills of social awareness, particularly through a module focused on workplace problem-solving, so that participants gain a greater ability to identify for themselves certain soft skills they need to have in their repertoire for particular social situations. The extended course time of our new curriculum is intended to provide more opportunities for skills to be practiced multiple times in different contexts, strengthening their development. Finally, the instructor training materials emphasize the importance of instructors modeling these skills in their own lives and in their mentorship relationships with youth participants.

All these pedagogical elements are explicit within the curriculum's trainer guide, including step-by-step instructions to facilitate the many learner-centered activities. Nonetheless, World Learning recognizes that offering effective soft skills programming depends greatly on the quality of instructor training and finding ways to expand implementation over time. Advancing in this area has required nimble responses to institutional and funding constraints, as discussed in the following section.

\section{Sustainability and Scale}

Over time, we have sought a variety of means to institutionalize and scale up our soft skills programming in Algeria, ultimately reaching over 22,000 youth around the country. This scaling up process began with a recognition of the obstacles standing in the way to incorporation by the state-run education system, which was the focus of our first project. In addition to significant bureaucratic challenges, such as universities' inability to hire career advisors since no such title existed in the 
government-approved university staffing structure, Algerian public universities simply proved largely unwilling to grasp that students' employability skills were a part of their concern. "Stop asking me to care whether our graduates are employable," one university rector told World Learning staff, "We are a research and academic institution" (World Learning, 2016). While changing this perspective of Algerian universities could be helpful for youth employment outcomes, we determined that this would have to be a longer-term goal.

Consequently, World Learning shifted strategy towards scaling up through private TVET institutes around the country, and also developed and published a career center toolkit, including our original soft skills curriculum, making this publicly available on the internet and through large-scale Youth Employment Summit events. As a result of these initiatives, certain other private educational institutions, as well as youth-led clubs, have begun to use these materials on their own initiative. The directors of TVET institutes whose career centers we supported also decided to create a National Career Center Federation, Techghil, to further promote these skills and opportunities for youth around the country.

Our most recent large-scale tracer study of 3601 of our youth program participants, conducted in 2019 while we were still finalizing our new curriculum, showed that among youth who independently sought employment, nearly $80 \%$ succeedednine percentage points higher than the official national youth employment rate. While these findings and our efforts at diffusion are promising, the reality is that further employability and soft skills curriculum testing and refinement will continue to be influenced by funder priorities as well as by the complex Algerian political and economic context, as the country struggles to recover from public protests, oil price shocks, and now the COVID-19 induced economic crisis.

\section{Philippines: Soft Skills Training and Empowerment Program (10ThousandWindows) ${ }^{10}$}

\section{Country Context}

Since 2010, the nonprofit organization 10ThousandWindows (10KW) has been implementing soft skills programming for survivors of violence and exploitation in the Philippines. The Philippines is a newly industrialized economy with one of the fastest growing economies in the region. While the Filipino economy has made advances in recent years, concerns regarding income inequality, underemployment, and reliance upon remittances from workers outside the Philippines persist. The

\footnotetext{
${ }^{10}$ Data presented in this case study were gathered as a part of 10ThousandWindows' internal processes as a nonprofit, following the organization's own internal ethics guidelines for data collected in-house.
} 
official national employment rate in the Philippines exceeds 90\%, but includes unpaid family workers along with self-employed workers and wage/salaried workers. It is estimated that $18.7 \%$ of youth aged 15-24 in the Philippines are unemployed and/or not engaged in education or training (PSA, 2019). Primary employment sectors include manufacturing, agriculture, and services, with substantial growth in the service sector such as business process outsourcing (DOLE, 2019).

In contrast to EDC and World Learning, $10 \mathrm{KW}$ focuses on a very specific population that includes youth but also extends beyond them. We primarily serve survivors of human trafficking-Filipino women and men who were trafficked within the Philippines or internationally to work in a variety of industries, like sex work, domestic work, or construction. Additionally, we serve survivors of intimate partner violence (IPV), child labor, and other forms of sexual and physical violence. We assist these survivors in preparing for and obtaining safe, sustainable employment. Lack of access to safe employment is a ubiquitous, fundamental concern for survivors of human trafficking, and strengthening access to safe employment is an important component of reducing vulnerability (Cordisco Tsai, 2017; Lisborg, 2009; Richardson et al., 2009). While the educational levels and ages of our participants vary, the majority are young adults in their 20s who have not completed secondary school upon enrolling in our programs. Participants in our programs prepare for formal employment in a wide range of industries, and each participant's career path is individualized to his or her interests, competencies, and goals.

Our services for survivors include career counseling, soft skills training, formal and non-formal secondary school and college scholarships and academic support, employment counseling, employer engagement and network building, education regarding labor rights, work immersion opportunities, and crisis intervention. All survivors newly enrolled at $10 \mathrm{KW}$ participate in a foundational four-month training program called the Soft Skills Training and Empowerment Program (STEP), which will be discussed in this case study. STEP is only one component of our comprehensive array of services aimed at supporting survivors in achieving their own goals, including an initiative we have launched to educate employers about trauma and help employers create trauma-informed workplaces so that survivors' experiences of trauma are not perpetuated in the workplace.

\section{Contextualization}

Originally designed in 2009-2010, the initial version of STEP contained two components: career goal development and soft skills training relevant to school and workplace success. Upon completing this preliminary program, survivors proceeded to 10KW's other services. In 2018, we conducted a comprehensive program assessment. A key ensuing recommendation was to revise STEP to make it more suitable for survivors of human trafficking (Cordisco Tsai, 2018). From 2018 to 2019, we 
embarked on a systematic process for revising the STEP curriculum. Following completion of a literature review, we utilized World Learning's soft skills inventory tool (Honeyman, 2018) to formulate a survey to investigate how to prioritize soft skills. Survey respondents included $10 \mathrm{KW}$ staff and employers hiring for entrylevel formal employment positions $(n=40)$. Using the inventory, respondents ranked soft skills in order of importance and identified the most important skills, with definitions provided to establish common understanding. Employment partners were asked to share observations regarding $10 \mathrm{KW}$ program participants' strengths and areas for growth. Finally, we conducted focus group discussions with 15 survivors who had completed STEP and obtained employment to discuss their strengths, workplace readiness, and challenges encountered in the workplace, and to identify soft skills they deemed most important $(\mathrm{n}=15)$.

To solidify the final list of skills, we integrated feedback from survivors, staff, and employers, identifying skills prioritized by all groups. Significant consideration was given to the need to ensure the content was comprehensible and accessible in a four-month training program for a population who has experienced significant trauma. The four-month timeframe was deemed sufficient to cover the core components of the entire intervention at a foundational level without significantly delaying survivors' progress toward the next stages of our services. We decided to focus on intrapersonal, interpersonal, and cognitive/planning skills, encompassing the following specific skills: self-confidence, coping with stress, and self-discipline/control (intrapersonal); respecting others, teamwork, and resolving conflict (interpersonal); and managing time/tasks, responsibility, and decision making (cognitive/planning). Given survivors' histories of experiencing abuse, lessons on interpersonal skills such as respecting others and conflict resolution focused not only on adapting to another person, but also helping survivors prioritize their own safety and ensure their own needs were met.

Additionally, STEP was expanded beyond solely soft skills training to include a broader set of services deemed necessary to adapt the program for our target population. The revised version of the STEP curriculum entails five core components: expanded orientations and informed consent processes, career counseling and goal development, psychosocial education, soft skills training, and culminating activities (see Table 6.2). In the revised version, the career goal development component was broadened to include substantially more individualized sessions with counselors to further support survivors in developing individualized career goals over time. We added psychosocial education addressing key challenges for our participants, including understanding trauma, intimate partner and gender-based violence, substance use, suicidal ideation, and reproductive health. Given our target population, a foundational training focusing on soft skills only was deemed incomplete without enhancing individualized counseling services and education regarding systemic issues that deepen the vulnerability of our participants. A breadth of services follows the STEP program, as STEP alone is insufficient in ensuring survivors can access safe, sustainable employment. 
Table 6.2 Overview of STEP curriculum

\begin{tabular}{|c|c|c|c|}
\hline & & Group session & Individual session \\
\hline Month 1 & $\begin{array}{l}\text { Orientation and Informed } \\
\text { Consent }\end{array}$ & $\begin{array}{l}\text { General Orientation } \\
\text { Career Counseling } \\
\text { Orientation } \\
\text { STEP Orientation }\end{array}$ & $\begin{array}{l}\text { CC1: Informed } \\
\text { Consent } \\
\text { CC2: Getting to know } \\
\text { you }\end{array}$ \\
\hline Month 2 & $\begin{array}{l}\text { Goal Development and Career } \\
\text { Counseling (CC) }\end{array}$ & $\begin{array}{l}\text { Evaluate my strengths and } \\
\text { motivations 1 } \\
\text { Evaluate my strengths and } \\
\text { motivations } 2 \\
\text { Explore career options } 1 \\
\text { Explore career options } 2 \\
\text { Setting my vision } 1 \\
\text { Setting my vision } 2\end{array}$ & $\begin{array}{l}\text { CC3: Exploring my } \\
\text { track } \\
\text { CC4: Strengthening } \\
\text { my vision }\end{array}$ \\
\hline \multirow[t]{2}{*}{ Month 3} & Psychosocial Education & $\begin{array}{l}\text { Trauma } \\
\text { Substance use } \\
\text { Reproductive health } \\
\text { IPV } \\
\text { Human trafficking } \\
\text { Suicide }\end{array}$ & $\begin{array}{l}\text { CC5: Focusing on } \\
\text { goals }\end{array}$ \\
\hline & \multirow[t]{3}{*}{ Life Skills Training } & $\begin{array}{l}\text { Intrapersonal: } \\
\text { 1: Self-confidence } \\
\text { 2: Coping with stress } \\
\text { 3: Self-discipline } \\
\text { 4: Review/synthesis } \\
\end{array}$ & CC6: Action planning \\
\hline \multirow[t]{3}{*}{ Month 4} & & $\begin{array}{l}\text { Interpersonal: } \\
\text { 1: Respecting others } \\
\text { 2: Teamwork } \\
\text { 3: Resolving conflict } \\
\text { 4: Review/synthesis }\end{array}$ & \multirow[t]{2}{*}{$\begin{array}{l}\text { CC7: Determining } \\
\text { readiness }\end{array}$} \\
\hline & & $\begin{array}{l}\text { Cognitive/planning: } \\
\text { 1: Managing time/tasks } \\
\text { 2: Responsibility } \\
\text { 3: Decision making } \\
\text { 4: Review/Synthesis }\end{array}$ & \\
\hline & Culmination & $\begin{array}{l}\text { Career Case Conference } \\
\text { Culminating Activity }\end{array}$ & CC8: Next steps \\
\hline
\end{tabular}

Sessions facilitated by: Plain Text - STEP Training Manager; Bold - Career Counselors; Italics Social Worker

\section{Pedagogy}

Several key pedagogical principles guide our implementation. First, a safe and supportive environment is essential. Traumatic events can destroy a person's sense of autonomy and fundamental assumptions about safety in the world (Herman, 1997). Survivors of human trafficking suffer from trauma symptoms, including anxiety, depression, terror, self-harm, attention difficulties, hostility, hypervigilance, difficulties identifying social cues, desperation to form relationships, emotional detachment, and helplessness (Clawson \& Goldblatt, 2007; Kiss et al., 2015a, b; Moore 
et al., 2017). These trauma responses can interfere with the process of learning and embodying soft skills. Key principles of a trauma-informed approach to creating an environment conducive to working with survivors include emotional and physical safety, transparency and trustworthiness, choice/restoration of autonomy and control, collaboration, empowerment, and sensitivity to cultural, historical, and gender issues (Herman, 1997; SAMHSA, 2014).

Trauma-informed principles influenced the collaborative process that $10 \mathrm{KW}$ engaged in to identify the focal soft skills. Trauma-informed principles are integrated through the way in which the training is structured and facilitated-the informed consent process, wording of modules, session facilitation, activity design, setting group norms, mechanisms for providing feedback, and expectations for communication with survivors. For example, 1 month is dedicated to the informed consent process so that survivors can make an informed decision of whether or not they want to participate in STEP. Individualized career counseling sessions are included in the STEP curriculum so that survivors can partner with and receive support from staff in setting individualized goals for themselves and their participation in STEP. Soft skills are discussed in relation to survivors' own goals for themselves. Trauma-informed principles also influence session facilitation in numerous ways. For example, at the outset, $10 \mathrm{KW}$ staff facilitate a collaborative conversation with survivors regarding group norms that can guide all participants' interactions with each other to ensure that a safe and supportive environment is cultivated in the classroom. During group discussion and activities, survivors are invited to participate in group activities only to the extent that they feel comfortable and as they are ready. Affirmations are provided each time survivors share or participate. Staff ask permission before providing information to reinforce a sense of autonomy for survivors in the classroom, and to ensure they are comfortable with all activities.

Additionally, all of our services, including STEP, are designed to adhere to a culturally-adapted form of Motivational Interviewing (MI), an evidence-based, person-centered, and humanistic approach to communication designed to strengthen an individual's commitment to growth (Cordisco Tsai \& Seballos-Llena, 2020; Miller \& Rollnick, 2013). The MI spirit is based upon four components: partnership, acceptance, compassion, and evocation. The final principle reflects a commitment to evoke a person's own motivation and goals rather than imposing them from the outside. In addition to using a trauma-informed framework, the integration of MI skills into session design and facilitation reinforced a supportive and safe learning environment.

Our pedagogy is also consistent with other effective practices identified in Table 6.1, introduced earlier. Staff are intentional in providing consistent, positive feedback. People who have experienced trauma may misinterpret interactions as threatening or negative, undermining a sense of competency or safety (CODCHU, 2016). As survivors often struggle with shame and low self-worth, feedback is provided in a manner that will not amplify these feelings and affirmations are integrated in an MI-adherent manner (Gill \& Cordisco Tsai, 2018). Staff are supervised to ensure that communication is warm, empathetic, and consistent (Ziegler, 2002). 
10KW's staff development program includes MI training and monthly MI learning communities in which staff practice implementing MI skills.

We also ensured that the curriculum was connected to an overarching purpose. During STEP, survivors engaged in individualized goal development wherein they developed personalized visions and career plans with support from counselors. STEP sessions were linked to survivors' goals for their own lives, supporting selfdetermination. Additionally, we promoted skills development through experiential learning integrated with reflective analysis and planning for further action. Experiential learning activities include role playing, simulation exercises, teambuilding games, and solving real-life case studies. Group processing is facilitated after each activity. At the end of each soft skill session, survivors are given at-home application exercises that can be done in the next three days. The outputs of at-home exercises are processed during the review/synthesis session for each soft skill cluster.

The arts were incorporated into the learning process, with survivors expressing their thoughts and feelings through drawings, collages, poems, essays, and individualized learning portfolios. Other $10 \mathrm{KW}$ programs, such as career counseling and supported work immersion, provided ongoing opportunities to strengthen soft skills over time, while the employment engagement side of $10 \mathrm{KW}$ 's operations focused on helping employers create trauma-informed workplace environments.

\section{Sustainability and Scale}

Given the distinctive experiences and needs of our target population, scaling the STEP intervention and integration with broader systems remains challenging. When serving a population that has experienced considerable trauma, substantial capacity building is required to prepare systems - including educational institutions, employers, and social welfare organizations - to successfully engage. Training, sensitization, and de-stigmatization surrounding mental health is needed, along with efforts to equip stakeholders in using trauma-informed methods. As referenced earlier, we launched a program to educate employers on how to create trauma-informed workplaces. While there has been heightened attention to mental health issues in the Philippines since the passage of the country's first mental health legislation in 2018, discussions about trauma and how trauma may impact employment-related soft skills are rare. The process of institutionalizing learning about mental health and trauma across a wide range of employers in diverse industries is a complex endeavor for a small nonprofit organization with limited funding.

Further, effective pedagogy requires significant investment of resources that are often not available. We previously used a train-the-trainer model for STEP, supporting other social welfare organizations in facilitating STEP. However, we deliberately transferred all facilitation of STEP in-house due to the need to ensure the training is implemented in a trauma-sensitive and MI-adherent manner, so that it is ultimately effective for survivors. Proper adherence to the program's guiding 
frameworks - a trauma-informed approach and MI - requires facilitators who have the knowledge, experience, and clinical skills required to implement traumainformed and MI-adherent programming. These approaches are still nascent within broader systems, and require significant strengthening of the clinical skills of facilitators to ensure programming is implemented in a manner that adheres to these approaches. While training and mentoring can be provided on MI and traumainformed care for other social welfare institutions, supportive organizational cultures and strong staff development systems are also required to ensure that facilitators have the training, clinical skills, and clinical supervision needed to successfully implement such approaches (Cordisco Tsai \& Seballos-Llena, 2020).

When considering sustainability and scale, we are speaking from the perspective of practitioners implementing soft skills programming with a very specific population - survivors of violence and exploitation, and primarily survivors of human trafficking. Our experiences facilitating STEP with survivors are not necessarily transferable to soft skills programming more broadly. Ultimately, the decision to move facilitation internally was deemed necessary to improve training quality for our specific target population while we continue to work on broader community education and systems change efforts. However, this shift augmented the cost of services, raising concerns for donors unfamiliar with the on-the-ground realities of working with survivors of human trafficking, who also expect a lower cost-perparticipant ratio than is realistic given the level of service specialization required. Questions remain about ensuring sustainability of this approach, as well as educating donors and other stakeholders in understanding the unique complexities of working with our target population. Despite challenges, we continue to prioritize strengthening our curriculum, ensuring suitability for survivors, enhancing evaluation methods, and embedding soft skills training within a comprehensive range of services to support survivors in achieving their own goals.

\section{Discussion and Conclusion}

These case studies, featuring soft skills curriculum for employability in three diverse contexts - Rwanda, Algeria, and the Philippines - raise important questions about such programming, including contextual decisions about what specific skills what specific skills to teach with particular populations and program goals, how to enact pedagogical principles, and how to ensure sustainability and scale both within formal education systems and outside them. Our work on each of these aspects, and likely the work of many other donor-supported soft skills programs, has also been influenced by the dynamics of the international community of practice we belong to, which is shaped by power and positionality-reflected in curricular frameworks first produced in wealthy developed countries, research promoted by influential institutions, and projects delimited by funder priorities and time horizons, as well as by organic connections and learning within and among implementing organizations. Acknowledging the existence of these dynamics gives a fuller picture of the 
influences and constraints shaping soft skills programming in the workforce development field.

While our professional community of practice has developed a shared understanding of soft skills that is influenced by donor priorities, these case studies also illustrate that implementing organizations can work effectively with local partners to contextualize their programs, moving through and beyond donor discourse. Many approaches to employability and soft skills curricula within our broader community of practice may have initially been developed either based on US-centered educational strategies, or on field staff insights into their own program contexts, but in either case with little context-specific research available for orientation. In the years since, programs have had to adjust their approaches to respond to both stronger funding agency guidance around specific skills to teach globally, as well as to a more nuanced understanding of local public and private sector priorities. In addition, as many organizations seek to offer their programming in multiple countries, they must face the challenges of maintaining a core curricular approach that is still contextually-responsive. The professional spaces that have shaped our broader community of practice in both intentional and organic ways-conferences, webinars, workshops, email listservs, and indeed the co-authoring of publications such as this one-continue to provide important contexts for learning about and adopting shared practices, as well as articulating and defending legitimate differences of approach and contextualization.

All three cases featured here have illustrated the resource constraints that affect the possibility of such contextual curriculum adaptation. Donor funding and project timeline expectations often do not prioritize curriculum revision, while a quality process can take many months of staff time from more than one person, including for desk reviews, field research, stakeholder engagement, and the detailed analysis and rewriting process, not to mention issues of translation and other details such as locally-adapted illustrations. Donor priorities may also shift significantly from one project to the next, while funding may be awarded to different organizations from project to project in the same context, risking the need for each new project to create a new curriculum from scratch. When powerful actors in the workforce development space overlook these issues, they contribute to maladapted programs that do not respond to the actual needs of participants. Further, they may perpetuate dynamics of cultural imperialism as a result, such as teaching workplace etiquette in a manner that reflects Western assumptions and patterns of behavior rather than a deep understanding the diverse norms that exist around the world with regard to issues such as negotiation, conflict management, authority, and politeness.

Another challenge that international workforce development programs face in creating effective employability and soft skills curricula is the issue of pedagogical fidelity in the enacted curriculum. Although there is increasingly greater clarity around the pedagogical practices and program designs that are more effective for developing specific targeted soft skills, it is often difficult to ensure these conditions are met. Projects must spend significant time and resources on training instructors in methodologies that are often not standard practices within the wider education and training systems of most countries of implementation. Furthermore, soft skills 
instruction requires much more than just mastery of some information and content. Instructors themselves must demonstrate these skills and attitudes in their own lives, and be able to mentor others through example as they develop them-often unevenly and organically_over time. Additionally, while cascade training models_-in which an organization trains master trainers, who in turn teach other instructors - are often used because they are a more cost-effective means of reaching larger numbers of beneficiaries, sometimes this strategy must be abandoned in order to reach the desired quality of experience for project participants, as $10 \mathrm{KW}$ found. The degree of pedagogical reorientation required to effectively teach soft skills cannot always be feasibly accomplished without significant investments in instructor training, a point that holds significant time and resource implications for teaching soft skills in both informal systems and formal educational institutions.

Issues of pedagogical fidelity become even more challenging as one considers the effort to institutionalize and significantly scale up the offering of employability and soft skills curricula to large populations. EDC's experience shows the importance of thinking about the wider system and delivery model at the same time as making content adaptation choices. It often seems like an improvised dance, struggling to balance between the elements and constraints of a system on the one hand, and an organization's view of the ideal pedagogical methodology on the other, in order to design an approach that can be implemented in reality. Not only instructor training systems must be considered in the effort to scale up, but also realistic costing of staff time and materials. Identifying future budget sources for such needs, fitting within school timetables, integration within national frameworks and assessments, addressing institutional cultures that may lead to resistance to new approaches, and monitoring and support mechanisms to ensure quality delivery all pose significant challenges-often within institutions that do not have such mechanisms functioning strongly even for their core educational priorities.

Beyond simply adding a new course to an existing education or training system, our cases show that employability and soft skills development could be more fully integrated into the system as a cross-cutting focus of instruction, or even through a wholehearted overhaul of general teacher pedagogy. In our experience of implementing soft skills programs in multiple contexts, many soft skills are actually best built over a long period of time, and may be developed through year-after-year exposure to a more student-centered pedagogy that requires students to be involved in research, problem-solving, discussion, and group work. Short-term projects may influence these broader practices as unintended beneficial effects but most often, this requires significant intentionality and support for institutional change that may only be achieved through embeddedness in longer term reorientation of the general educational system - again a dynamic that requires a rare long-term continuity in funding and program purpose.

While continuing to grapple with issues of contextualization, pedagogy, and sustainability and scale, many organizations are also experimenting with alternate methodologies for soft skills development that respond to particular programming needs, constraints, and opportunities. World Learning, for example, is working with extended narratives-fictional stories focusing on characters and the challenges 
they confront over the course of several linked episodes or chapters-in conjunction with individual and group activities, to effectively model the skills participants can develop and to help participants visualize and practice, in an enduring way, the decisions they may make in their own lives (similar to the strategy of case studies described in Pacheco \& Murphy-Graham, Chap. 10, this volume). Similarly, EDC partnered with Search for Common Ground in Rwanda to develop a radio series that used a soap opera style to emphasize many of the core skills found in the WRN curriculum. By following a character's story, participants share an "experience" external to themselves that serves as a touchpoint for skill-development exercises and discussion, enriching the learning experience in new ways.

Virtual reality, roleplay smartphone apps, and other online learning modalities also offer new prospects for scaling up soft skills development curricula, while still posing challenges for universal access and for approximating the rich social interactions that can more naturally occur in face to face programs (see, for example, Haley-Robbins et al., 2019). These contemporary approaches to soft skills development coexist with broader concerns about technological change and the future of work, offering the tantalizing prospect of building digital literacy and other contemporary technology skills at the same time as employability and soft skills. However, moving to these digital platforms requires careful thinking about how to preserve the learner-centered pedagogy and sense of community and confidence-building that comes from being a part of a learning group. As automation, artificial intelligence, increasingly ubiquitous broadband access, and post-COVID 19 changes to labor markets are accelerating shifts in skills demand within and across sectors, especially with respect to the application of digital skills, these new frontiers for soft skills development cannot be overlooked, even as they are by no means a panacea.

Regardless of the approach, there remains more to explore in the effort to understanding the on-the-ground challenges that soft skills initiatives face, as well as the best way forward as such programming navigates an international field of power and influence, works towards contextual grounding in local research, and seeks ways to achieve and sustain new pedagogical approaches with broader populations.

Acknowledgements World Learning acknowledges the support of the U.S. Department of State and its Middle East Partnership Initiative (MEPI) in funding the projects and research described in our case study. The views expressed in this chapter are those of the author and do not represent the views of, and should not be attributed to, the U.S. Department of State or MEPI. World Learning Algeria field office staff who played a central role in the research and curriculum development processes described in the chapter include Andrew Farrand, Hamza Koudri, Mehdi Bentoumi, Zobida Tadj, Latifa Dehane, Abdallah Talhi, and Leah Bitat.

EDC acknowledges funding support from USAID and the MasterCard Foundation for the projects described in Rwanda, as well as contributions from Beth Miller Pittman, a technical advisor on the project, and Nora Nunn, a reviewer of the case study. The views expressed in this chapter are those of the author and do not represent the views of, and should not be attributed to, USAID or MasterCard Foundation.

$10 \mathrm{KW}$ acknowledges the contributions of Jonna Eleccion (Director of 10KW Philippines) and Rosa Gabriela Benares (STEP Training Manager at 10KW). 10KW did not receive any specialized funding for the work relevant to the case study. 


\section{References}

Alcid, A., \& Martin, G. (2017). Akazi Kanoze work readiness and employment outcomes: A randomized controlled trial of secondary school students in Rwanda. Education Development Center.

Bourdieu, P. (1972). Outline of a theory of practice. Cambridge University Press.

Bourdieu, P. (1986). The forms of capital. In J. Richardson (Ed.), Handbook of a theory of research for the sociology of education (pp. 241-258). Greenwood Press.

Bourdieu, P. (1990). The social conditions of the international circulation of ideas. In R. Schusterman (Ed.), Bourdieu: A critical reader (pp. 220-228). Blackwell.

Clawson, H. J., \& Goldblatt, G. L. (2007). Finding a path to recovery: Residential facilities for minor victims of domestic sex trafficking. Human Trafficking Data and Documents, 10. https:// aspe.hhs.gov/system/files/pdf/75186/ib.pdf

CODCHU Center on the Developing Child at Harvard University. (2016). Building core capabilities for life: The science behind the skills adults need to succeed in parenting and in the workplace. http://www.developingchild.harvard.edu/

Cordisco Tsai, L. (2017). The process of managing family financial pressures upon community reentry among survivors of sex trafficking in the Philippines: A grounded theory study. Journal of Human Trafficking, 3(3), 211-230.

Cordisco Tsai, L. (2018). 10ThousandWindows 2018 program assessment. 10ThousandWindows.

Cordisco Tsai, L., \& Seballos-Llena, I. F. (2020). Reflections on adapting motivational interviewing to the Filipino cultural context. Practice: Social Work in Action, 32(1), 43-57.

CREAD \& ILO. (2017). Rapport principal de l'enquête algérienne sur la jeunesse. Unpublished Report.

DOLE Department of Labor and Employment. (2019). Labor Market Profile. Issue, 1. http:// ble.dole.gov.ph/downloads/Publications/LMI-LMP-2018\%20PH\%20Labor\%20MarketMarch\%202019\%20Issue.pdf

Farrand, A. (2019). Algeria youth employment project: Labor market assessment. World Learning. Gill, M., \& Cordisco Tsai, L. (2018). Building core skills among adult survivors of human trafficking in a workplace setting in the Philippines. International Social Work, 63(4), 538-544. https://doi.org/10.1177/0020872818819043

Gumperz, J. J., \& Levinson, S. C. (1996). Rethinking linguistic relativity. Cambridge University Press.

Haley-Robbins, Z., Honeyman, C. A., \& Murillo, K. (2019). 10 apps to build employability and soft skills. World Learning.

Herman, J. (1997). Trauma and recovery: The aftermath of violence - From domestic abuse to political terror. Basic Books.

Honeyman, C. A. (2016). The orderly entrepreneur: Youth, education, and governance in Rwanda. Stanford University Press.

Honeyman, C. A. (2018). Soft skills development: Guiding notes for project and curriculum design and evaluation. World Learning.

Honeyman, C. A. (2019). Soft skills for youth employment in Algeria: Qualitative research report. World Learning.

Honeyman, C. A., \& Fletcher, E. (2019). Measuring skills for youth workforce development. USAID.

Ignatowski, C. (2017). What works in soft skills development for youth employment? A donor's perspective. Youth Employment Funder's Group in partnership with the MasterCard Foundation.

Kautz, T., Heckman, J., Diris, R., ter Weel, B., \& Borghans, L. (2014). Fostering and measuring skills: Improving cognitive and non-cognitive skills to promote lifetime success. OECD.

Kiss, L., Pocock, N. S., Naisanguansri, V., Suos, S., Dickson, B., Thuy, D., Koehler, J., Sirisup, K., Pongrungsee, N., Nguyen, V. A., Borland, R., Dhavan, P., \& Zimmerman, C. (2015a). Health of men, women, and children in post-trafficking services in Cambodia, Thailand, and Vietnam: An observational cross-sectional study. The Lancet Global Health, 3(3), e154-e161. 
Kiss, L., Yun, K., Pocock, N., \& Zimmerman, C. (2015b). Exploitation, violence, and suicide risk among child and adolescent survivors of human trafficking in the Greater Mekong Subregion. JAMA Pediatrics, 169(9), e152278-e152278.

Kolb, D. (1984). Experiential Learning: Experience as the source of learning and development. Prentice Hall.

Lave, J., \& Wenger, E. (1991). Situated learning: Legitimate peripheral participation. Cambridge University Press.

Lippman, L., Ryberg, R., Carney, R., \& Moore, K. (2015). Key “soft skills” that foster youth workforce success: Toward a consensus across fields. WorkForce Connections. FHI 360/USAID.

Lisborg, A. (2009). Re-thinking reintegration: What do returning victims really want and need? Strategic Information Response Network United Nations Inter-Agency Project on Human Trafficking (UNIAP).

MasterCard Foundation. (2017). Skills at scale: Transferable skills in secondary and vocational education in Africa.

Miller, W. R., \& Rollnick, S. (2013). Motivational interviewing: Helping people change. Guilford Press.

Moore, T., McArthur, M., Death, J., Tulbury, C., \& Roche, S. (2017). Young people's views on safety and preventing abuse and harm in residential care: "It's got to be better than home.". Children and Youth Services Review, 81, 212-219.

ONS. (2018). Activité, Emploi \& Chômage en Septembre 2018. Office National des Statistiques, Algeria. Accessed October 2018 from this website: http://www.ons.dz/IMG/emploiseptembre2018.pdf.

PSA Philippines Statistics Authority. (2019). Youth population and labor participation. http:// www.psa.gov.ph/content/employment-rate-july-2019-estimated-946-percent

Richardson, D., Poudel, M., \& Laurie, N. (2009). Sexual trafficking in Nepal: Constructing citizenship and livelihoods. Gender, Place and Culture, 16(3), 259-278.

Roberts, R., Martin, J., \& Olaru, G. (2015). A Rosetta stone for noncognitive skills: Understanding, assessing, and enhancing noncognitive skills in primary and secondary education. Asia Society. http://asiasociety.org/files/A_Rosetta_Stone_for_Noncognitive_Skills. pdf?_sm_au_=iVVbvrLb7qLPqPMQ

SAMHSA Substance Abuse and Mental Health Services Administration. (2014). SAMHSA's concept of trauma and guidance for a trauma-informed approach (HHS publication no. (SMA) 14-4884). Substance Abuse and Mental Health Services Administration.

Soares, F., Babb, S., Diener, O., Gates, S., \& Ignatowski, C. (2017). Guiding principles for building soft skills among adolescents and young adults. USAID YouthPower Implementation.

Stites, R. (2011). EDC international work readiness framework and assessment - Notes on the "state of the art" in 21st century work readiness standards and assessments. Unpublished internal report. Education Development Center.

UNICEF. (2012). Global evaluation of life skills education programmes. United Nations Children's Fund.

World Bank. (2019). World development report: The changing nature of work. World Bank.

World Bank. (2020). World Bank data, share of youth not in education, employment or training, total (\% of youth population). Via International Labour Organization, ILOSTAT database. https://data.worldbank.org/indicator/sl.uem.neet.zs

World Economic Forum. (2018). The future of jobs report. https://www.weforum.org/reports/ the-future-of-jobs-report-2018

World Learning. (2016). Promoting Education, Altruism and Civic Engagement (PEACE) final performance report. World Learning.

YouthStart. (2016). Youth economic opportunity ecosystem analysis Rwanda via UNCDF. https://www.un.org/youthenvoy/2016/01/youth-economic-opportunity-ecosystemanalysis-rwanda-via-uncdf/

Ziegler, D. (2002). Traumatic experience and the brain: A handbook for understanding and treating those traumatized as children. Acacia Publishing Inc. 
Open Access This chapter is licensed under the terms of the Creative Commons Attribution 4.0 International License (http://creativecommons.org/licenses/by/4.0/), which permits use, sharing, adaptation, distribution and reproduction in any medium or format, as long as you give appropriate credit to the original author(s) and the source, provide a link to the Creative Commons license and indicate if changes were made.

The images or other third party material in this chapter are included in the chapter's Creative Commons license, unless indicated otherwise in a credit line to the material. If material is not included in the chapter's Creative Commons license and your intended use is not permitted by statutory regulation or exceeds the permitted use, you will need to obtain permission directly from the copyright holder. 